\title{
An Extension to UML for the Modeling of Web Based Bus Reservation System
}

\author{
Hussain Mohammad Abu-Dalbouh and Sulaiman Abdullah Alateyah \\ Department of Computer Sciences, College of Sciences and Arts in Unaizah, Qassim University, \\ Al-Qassim, Kingdom of Saudi Arabia
}

Article history:

Received: 22-03-2020

Revised: 02-06-2020

Accepted: 01-07-2020

Corresponding Author: Hussain Mohammad Abu-

Dalbouh

Department of Computer

Sciences, College of Sciences and Arts in Unaizah, Qassim University, Al-Qassim, Kingdom of Saudi Arabia Email: hussainmdalbouh@yahoo.com

Sulaiman Abdullah Alateyah Department of Computer Sciences, College of Sciences and Arts in Unaizah, Qassim University, Al-Qassim, Kingdom of Saudi Arabia Email: salateyah@qu.edu.sa

\begin{abstract}
Bus reservation system had actualized in different nations for years, at first from manual to automated reservation system. Online bus ticketing and reservation administrations are adequately expanding in the market since it was propelled by Park May. Now, numerous individuals and organizations are beginning to gain insights of the express bus reservation system. Considering the bus ticket reservation system that has experienced a constant development in the recent years, nevertheless the means for their specifications are still underdeveloped. The Unified Modeling Language (UML) is a language for the specification, visualization and documentation of object-oriented software systems. There is a lot of potential value in UML and diagrams in general. Existing UML diagrams can be utilized to helpfully display conduct. Therefore, in order to understand the development of bus reservation system, it is important to understand what the requirements are on the complete web based bus reservation system. Analyzing the web based bus reservation system by using UML diagrams. Consequently, the nature of theoretical models legitimately influences the nature of the comprehension of the application space and the nature of the last programming items that are at last dependent on them. In this study, we present (web based bus reservation systemUML), the proposed extension to UML covers aspects of use case diagram, sequence diagram, activity diagram and class diagram of the web based bus reservation at the various views and diagrams of UML.
\end{abstract}

Keywords: Models, Unified Modeling Language, System, Analysis, Example, Modification, Developing, Design, Programming

\section{Introduction}

The Unified Modeling Language identifies a set of standards for modeling object-oriented systems to draw diagrams, notation and defines the underlying semantics of the meaning of these diagrams and symbols (Booch et al., 2005). Now, in order to learn there is a standard notation for modelers, instead of using many notations and methods for object-oriented design. UML could be utilized to demonstrate different sorts of frameworks including software systems, hardware systems and realworld organizations. The infiltration of programming serious systems into almost every aspect of life has seen software development practice reached out to counter the ever-expanding complexity nature of such software development and satisfy the expanding request.

In a rather improvement condition, the progress from idea to run execution needs to satisfy the market need quickly, simultaneously the software should show the required characteristics of vigor, practicality and meet different determinations, including usability and performance demands. Governments and profit organizations are chasing the time and other competitors to automate their systems and provided services such as transportations, health care and taxation. In addition, the bus ticketing and reservation system is one of the rapid growth markets which is requested by many countries. People are willing to adopt and use electronic systems due to the perceived ease of use and usefulness of using such systems from their smart devices. Thus, it is essential that on these platforms computer architects and designers for analyzing the features of the applications users have generally expected.

Governments and companies who providing transportation services such as the express bus have to serve more customers than ever before. That would be 
practically impossible without enhancing their equipment and technology. Transportation administrators are therefore continually searching for the most recent innovation, which will continue to increase revenues. In the express bus administration, an issue that might slow down the work place is attempting to keep track of what is happening throughout the reservation system with every costumer. Their stations, vehicles, ticket kiosk and other services including general information such as maps and destinations are required to keep the flow of transport services moving. Delaying this development can cause over the top wastes in the all-out system of their organizations and pay. That is the inspiration driving why programming associations search for new and overhauled ways to deal with assistance transportation providers in much better supervising staff and time obstacles.

Bus reservation systems are becoming increasingly important; nevertheless, the means for their requirements are still underdeveloped. Hence, having clear and standardized behavioral requirements of bus reservation system would make it possible to determine the properties and make them more comprehensive and less expensive. Such specifications, unfortunately, are barely used. The correspondence between a specification and the software itself is even less frequent. Much of what can technically be known as system specification is actually being done with use cases in industry. Use cases are an essential tool to capture software system behavioral requirements. They are informal depictions usually written in natural language and thus they lack rigor and reasonableness of system properties. In the current study, we look at delivering the benefits of behavioral specification practices to bus reservation on customer progress system by showcase the system analysis and design as identified by the UML (OMG 2000). It analyses UML diagrams and provides a Use-Case-driven approach to how these diagrams are used on web based bus reservation system. In the various views and diagrams of UML, we present (web based bus reservation system), our proposed extension to UML covering reservation aspects. The use of web based bus reservation system-UML is demonstrated by means of reservation system.

In this study illustrated Web based bus reservation system-UML using to have meaningful and standardized behavioral specifications of resevation system would make it feasible to determine the properties and enable more thorough and less costly. Web based bus reservation system-UML help to figure out what really need for analyzing, designing, modeling and figure out how to take something that is complicated, even messy and turn it into something precise enough that can do.

\section{Motivation and Study Questions}

UML is a powerful tool that can greatly improve the quality of the systems analysis and design and it is aimed that the improved practices will translate into higherquality systems. By using UML iteratively in analysis and design, can achieve a greater understanding between the business team and the IT team regarding the system requirements and the processes that need to occur in the system to meet those requirements. Unified Modeling Language is used to specify, visualize, modify, construct and document the artifacts of an object-oriented software-intensive system under development. During this different diagrams are drawn according to need \& the types of requirement. The need of this study is to find out the importance of different diagrams (class, use-case, use case specification, sequence and activity) during software development. Why is it important to study Unified Modeling Language? What are the benefits of studying Unified Modeling Language? How can addresses Unified Modeling Language in system analysis and design? How can adopt UML to understand and analysis the systems? The goal of this paper is understand the development of bus reservation system. Therefore, it is important to understand what the requirements are on the complete web based bus reservation system. In addition, analyzing the web based bus reservation system by using UML diagrams. Thus, in this study, we present (web based bus reservation system-UML).

\section{Purpose of the Study}

The Unified Modeling Language (UML) is a language for the specification, visualization and documentation of object-oriented software systems. There is a lot of potential value in UML and diagrams in general. For building objectoriented programming, the Unified Modeling Language has become the accepted standard. This paper is meant to be used as a starting point to help how to use Unified Modeling Language notations. It reviews the diagrams that comprise Unified Modeling Language (UML) and offers a Use-Case-driven approach on how these diagrams are used to web based bus reservation system.

The purpose of this paper is to showcase the system analyses and design of concept of a web based bus reservation system. It also, a precise form of systemlevel operation specification and an operation schema declaratively describes the effects of a system operation by using case model, actors, relationships between the actors and the use case, interaction between the actors, sequence, activity and class diagrams of Web Based Bus reservation system as defined by the Unified Modeling Language (UML).

\section{Literature Review: UML in Brief}

A background information about the Unified Modeling Language (UML) which standardized by the Object Management Group (OMG) is given along with web based bus reservation system. Then the related work is mentioned. 
The UML, in brief, is a standard of true programming industry, which demonstrating language for visualizing, determining, developing and archiving the components of frameworks mostly and programming frameworks specifically (Booch et al., 2005). UML has a perfect characterized grammar and semantics. It offers a rich arrangement of conceptual antiquities to help in the clarification and top-down optimization of item situated programming frameworks from prerequisites catch to the organization of programming parts.

For building object-oriented programming, the Unified Modeling Language (UML) has become the accepted standard. UML is expanding on the now profoundly effective standard, which has become an industry norm for demonstrating, structuring and developing programming frameworks just as business and logical procedures have been progressively summed up. UML has a well-defined structure of the language and semantics. This gives a lot of ancient graphical rarities to aid in the elicitation and top-down refinement of organized article programming frameworks from grab necessities to sending programming segments.

The Object Management Group (OMG) particular expresses that The Unified Modeling Language (UML) is a graphical language for envisioning, indicating, building and reporting the ancient rarities of a product serious framework. The UML offers a standard method to compose a framework's outlines, including calculated things, for example, business procedures and framework works just as solid things, for example, programming language articulations, database mappings and reusable programming segments. UML characterizes thirteen forms of essential graphs divided into two general sets: Behavioral diagrams and structural modeling diagrams. This paper will address Web-based Bus Reservation System Use case, sequence, activity and class diagrams.

\section{UML Diagrams}

A diagram includes model elements, for instance, classes, objects, nodes, parts and relationships, represented by symbols of graphics. Moreover, a diagram may be utilized to explain such framework viewpoints at various levels of abstraction. A use case diagram in the web based bus reservation system, indicates the usefulness of the web based bus reservation system brings the user's perception to the table and characterized what should occur to different actors within our system. The UML diagrams which used here are described in brief below.

\section{Use case Diagram}

The use case diagram describes the features within the system and specifies the components of a system and its users. This displays the actors and their interaction with the system's functions. It likewise, a particular method for utilizing the system by operating some of the functionality and capturing software system behavioral requirements. The diagram is used to illustrate the modeling system's static behavioral parts of the use case perspective.

\section{Sequence Diagram}

This diagram depicts how the squares impart and portrays how each use case is provided by conveying objects. This reveals how the objects of the cooperation perceive the use case by their communication. It occurs as squares send upgrades between one another. The principle motivation behind the configuration of use cases is along these lines to characterize the conventions of the squares. It additionally, portrays a situation including different cooperating objects.

\section{Class Diagram}

This diagram shows the static class structure and their potential connections within the system. The class diagram shows the squares of structure of any object orientated system. It portrays a static view of the model or part of it, showing its attributes and behavior. As opposed to itemizing the techniques for accomplishing tasks. Class diagram are generally valuable in representing connections among interfaces and classes.

\section{Activity Diagram}

This outline demonstrates exercises and activities to illustrate workflows. Activity diagram depicts stepby-step work processes of parts in a system to the business and operational. Likewise, it shows the general control progression.

\section{Related Work}

Software architects and engineers are facing challenges on their works due to the growth complexity of information systems (Fuentes-Fernández and Vallecillo-Moreno, 2004). The concerns about the programming code quality ad-hoc the attention of software engineers on the modelling aspects of the process of system development (Fuentes-Fernández and Vallecillo-Moreno, 2004). According to Mubin et al. (2015) modeling is required to design web applications. A system description written in a well-defined language refers to a model (Fuentes-Fernández and VallecilloMoreno, 2004). In addition, (Fuentes-Fernández and Vallecillo-Moreno, 2004) stated that the Object Management Group (OMG) identifies many modeling languages, of which the most widely accepted and used Unified Modeling Language (UML) is possibly. The development of standards for several software engineering aspects, Unified Modeling Language (UML) for instance, has been proposed by the consortium of the Object Management Group (OMG) (Colomb et al., 2006). 
UML is a visual language for system artifacts to be specified, constructed and documented. It is a language for modeling that can be used with all major object and feature methods and can be extended to all application domains, including transportations and implementation platforms (Fuentes-Fernández and Vallecillo-Moreno, 2004). The Unified Modeling language is an extensible software design language including applications for web and database, modeling for business, data warehouses and legacy systems (Pathak et al., 2017). The design of web applications becomes challenging and raises many concerns, particularly with regard to modeling approaches (Mubin et al., 2015).

Abu-Dalbouh (2019; Abu-Dalbouh and Almueit, 2013; Abu-Dalbouh, 2013) discussed the functionality of the Mobile Tracking on Patient Progress System by using use case diagram. Abu-Dalbouh (2014a; 2014b) discussed (Mobile Tracking on Patient Progress SystemUML example), the study covered aspects of mobility from the different UML viewpoints and diagrams. AbuDalbouh (2018) describes the extensions made in each UML diagram, to allow the proposed system to be clearly described. Then, modifications to the UML. AbuDalbouh et al. (2019) are describing the functionality of the Electronic Health Record system by using use case diagram. Abu-Dalbouh et al. (2020) are describing the functionality of the Application of Physics Experiments of High School by Using Augmented Reality system by using use case diagram. Between 2001 and 2008, Pretorius and Budgen (2008), reviewed 33 articles providing empirical evidence on the use of UML diagrams and notations. They noticed that perception and measurements were the essential themes for experimenting using only the abstracts. The authors argued that the quality of the model and reception encounters worth more study. Concentrating on consistency in UML models only, 44 articles published between 2001 and 2007 were reviewed by (Lucas et al., 2009). That is, at least two UML charts crosssectional forming a complete UML model. They conclude that consistency of the UML model is a profoundly dynamic and promising research line, however there are some significant holes in writing. The researchers address these gaps by presenting a proper consistency the executives language. Mohagheghi et al. (2009) reviewed 40 primary studies published between 2000 and 2007. Their research inspected quality practices, the styles of models and modeling methods addressed in the literature and quality goals. In their reviewed papers the authors defined six quality goals: Correctness, completeness, consistency human and tool comprehensibility, confinement and changeability. They also acknowledged six quality approaches, the majority of which were UML models.

\section{Web Based Bus Reservation System UML by Example}

These days the web gets one of the most significant divisions around the globe. The web has changed the manner in which those individuals take a gander at the life. Utilizing the web reserves the spot frameworks the least demanding approach to carry out this responsibility. The web booking to travel toss plane or transport is currently in the scope of our hand at home.

The online Bus reservation provides better facilities to the travelling public. There are many existing features have been modified as given like the Advance booking being made for all long distance services. Difference new features have been included that covered under the online bus reservation system at a single counter irrespective of the starting point and destination of the traveler's starting point and finishing point of excursion and administration. Travelers will board the traveler's administration to the Start Place and reroute transport remains where appropriate. Synchronous booking of tickets for the onward and return trips is allowed. In the case of a gathering for example, name, age, gender, address, telephone number, email ID (discretionary) will be collected for the purpose of creating a traveler database and communication if emergencies arise.

Tickets can be dropped at any of the counters irrespective of the place of reservation, including franchisees subject to the following conditions: Cancelation at Franchisee counters until the production reservation is approved for that administration. Typically, this period will be a day of launch time of the administration at the Originating place. Tickets with limitations will be checked according to the above methodology. Nonetheless, the full entry of the ticket (not a restricted passage) would result in the crossing of charges and the discount amount will be toll collected less retraction costs. In addition, cancelation fees are as appropriate for legitimate tariffs as they were. Return Journey Discount of 10 per cent is offered only if the traveler both books ahead and travels all the time (in single exchange). The following paragraphs shows the extensions made in every one of the UML diagrams to permit the unequivocal portrayal of the proposed system. First, List the functional and non-functional requirements of the system. Then, modifications to the UML is shown. In the priority column, the following short hands are used:

- M-Mandatory requirements (something the system must do)

- D-Desirable requirements (something the system preferably should do)

- $\quad$ Optional requirements (something the system may do)

\section{Functional and Non-Functional Requirements}

The complete list of the system requirements (the functional requirements and Non-Functional Requirements) are shown in Tables 1 and 2 . 
Table 1: Functional requirements

\begin{tabular}{|c|c|c|c|}
\hline No. & Requirement ID & Requirement description & Priority \\
\hline & Ur_01 & Login: (Administrator, manager and buyers) & \\
\hline 1. & Ur_01_01 & The buyer must have log in account (register) to can login & M \\
\hline 2. & Ur_01_02 & The administrator must have login account (register) to can login & M \\
\hline \multirow[t]{2}{*}{3.} & Ur_01_03 & The manger must have login account (register) to can login & M \\
\hline & Ur_02 & Maintaining administrator: & \\
\hline 4. & Ur_02_01 & $\begin{array}{l}\text { The administrator must have login account to can add/ update trip } \\
\text { feature, manger information and price. }\end{array}$ & M \\
\hline 5. & Ur_02_02 & Administrator can update trip feature & $\mathrm{O}$ \\
\hline 6. & Ur_02_03 & Administrator can add and update the base price for trip and for each feature & $\mathrm{O}$ \\
\hline \multirow[t]{2}{*}{7.} & Ur_02_04 & Administrator can add and update the customer's details & $\mathrm{O}$ \\
\hline & Ur_03 & $\begin{array}{l}\text { See and select/view information: } \\
\text { (Customer, manger and buyer) }\end{array}$ & \\
\hline 8. & Ur_03_01 & $\begin{array}{l}\text { The customer can see and select trip, base/extra feature and safety feature } \\
\text { to get information about the reservation to calculate room price }\end{array}$ & $\mathrm{D}$ \\
\hline 9. & Ur_03_02 & $\begin{array}{l}\text { The manger must login to can view monthly reservation sales report and } \\
\text { see incoming order from buyer }\end{array}$ & $\mathrm{O}$ \\
\hline 10. & $\begin{array}{l}\text { Ur_03_03 } \\
\text { Ur_04 }\end{array}$ & $\begin{array}{l}\text { The buyer can locate nearest manger to his/her address } \\
\text { Operation: (Customer and buyer) }\end{array}$ & M \\
\hline 11. & Ur_04_01 & The customer must login to print sales report and see incoming order & $\mathrm{O}$ \\
\hline 12. & Ur_04_02 & The buyer must login to make reservist & $\mathrm{O}$ \\
\hline
\end{tabular}

Table 2: Non-functional requirements

\begin{tabular}{|c|c|c|c|}
\hline No. & Requirement ID & Requirement description & Priority \\
\hline & Ur_01 & Reliability issues: (Reservation and cost) & \\
\hline 1. & Ur_01_01 & The prices of the reservation include all the base features for specific trips & M \\
\hline \multirow[t]{2}{*}{2.} & Ur_01_02 & Each extra features, cost a specific price & M \\
\hline & Ur_02 & Usability issues & \\
\hline 3. & Ur_02_01 & Easy for end buyers to access & M \\
\hline 4. & Ur_02_02 & Can view the features and costs & M \\
\hline 5 & Ur_02_03 & Can view extra features & $\mathrm{O}$ \\
\hline 6. & Ur_02_04 & The systems should have a provision to configure and map the features with the trips & $\mathrm{D}$ \\
\hline 7. & Ur_02_05 & Administrator can make monthly reservation sales report & $\mathrm{O}$ \\
\hline \multirow[t]{2}{*}{8.} & Ur_02_06 & Administrator can see report of buyers, features every quarterly & $\mathrm{O}$ \\
\hline & Ur_03 & Security administrator & \\
\hline \multirow[t]{2}{*}{9.} & Ur_03_01 & No one can configure or map the features trips without the administrator & M \\
\hline & Ur_04 & Performance & \\
\hline 10. & Ur_04_01 & The system should have a high speed of manipulation data and reply to the user request & $\mathrm{M}$ \\
\hline
\end{tabular}

\section{Use Case Diagram}

To start a use case the on-screen actor must be related with a utilization case, since the actor who assumes responsibility to start the utilization case and this is appeared by an offered bolt from the actor to the use case. In addition, the use case embodies actor and use cases. Actors are outer elements collaborating with the web based bus reservation system through use cases. The usefulness of a system or subsystem for demonstrating the portrayed by a gathering of use cases. It denotes a functional requirement that may include at least one of the actors Based on the information requirement the Web Based Bus Reservation System has the following actors: Administrator, Buyers and Manager.

The Administrator actor can be interacting with the web based bus reservation system by pressing $<<\log$ in as Administrator $>>$. The Administrator should write his/her name and password to access the system from the page that the system shows it. Consequently, the Administrator interact with the services of the web based bus reservation system such as View Main Page, Manage Bus Schedule, Manage Manger Information, Delete Manager and Search Buyer and Manager Profile.

The second actor is Buyer can be interacting with the web based bus reservation system by pressing $<<$ Log in as Buyer $>$. The Buyer should write his/her name and password to access the system from the page that the system shows it. Consequently, the Buyer interact with the services of the web based bus reservation system such as View Main Page, Manage Bus Schedule, Booking Trip and Payment. 
The third actor is Manager can be interacting with the system by pressing <<Log in as Manager >>. The Manager should write his/her name and password to access the system from the page that the system shows it. Thus, Consequently, the Manager interact with the services of the web based bus reservation system such as View Main Page, Manage Bus Schedule, Search Buyer and reservist Information, Canceling Reservation, Update Reservation and Update Bus schedule. Figure 1 shows the use cases of the web based bus reservation system containing the three actors.

\section{Sequence Diagram}

It describes how each use case is offered by conveying objects. The diagram shows how the cooperation objects understand the use case through their communication. The connection happens as blocks send stimuli between each other. The principle motivation behind the use case configuration is therefore to characterize the conventions of the blocks (Booch et al., 2005; Rumbaugh et al., 1999; Oestereich, 2002; Scott, 2001).

In fact, for every use case/function in the system can have a sequence diagram. Therefor this study describes in Fig. 2 the Login as administrator. Figure 3 Update bus schedule, Fig. 4 Booking trip and Fig. 5 Payment sequence diagram shows that the buyer must choose trip and select it. Then, the system will respond to the buyer trip and will open page to view the bus schedule details. The system will respond to the buyer trip and will display the trip details. The buyer can select to pay by smart card or act. After that buyer, the presses submit to the system. The system will save all information then display the ticket. The buyer must print the ticket once the system display the ticket.

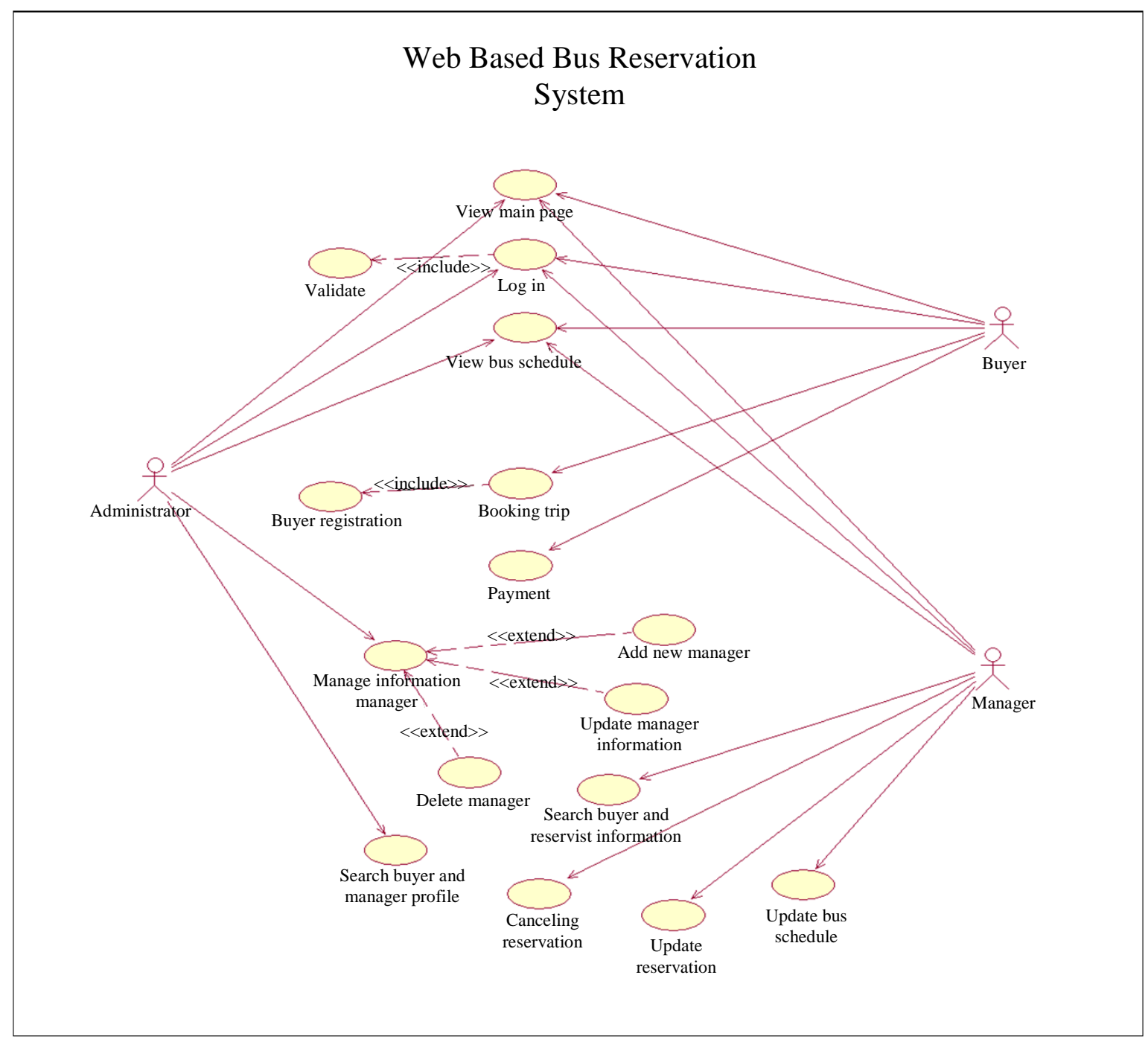

Fig. 1: Main use case (It shows that web based bus reservation system have many cases and some cases extended to other cases) 


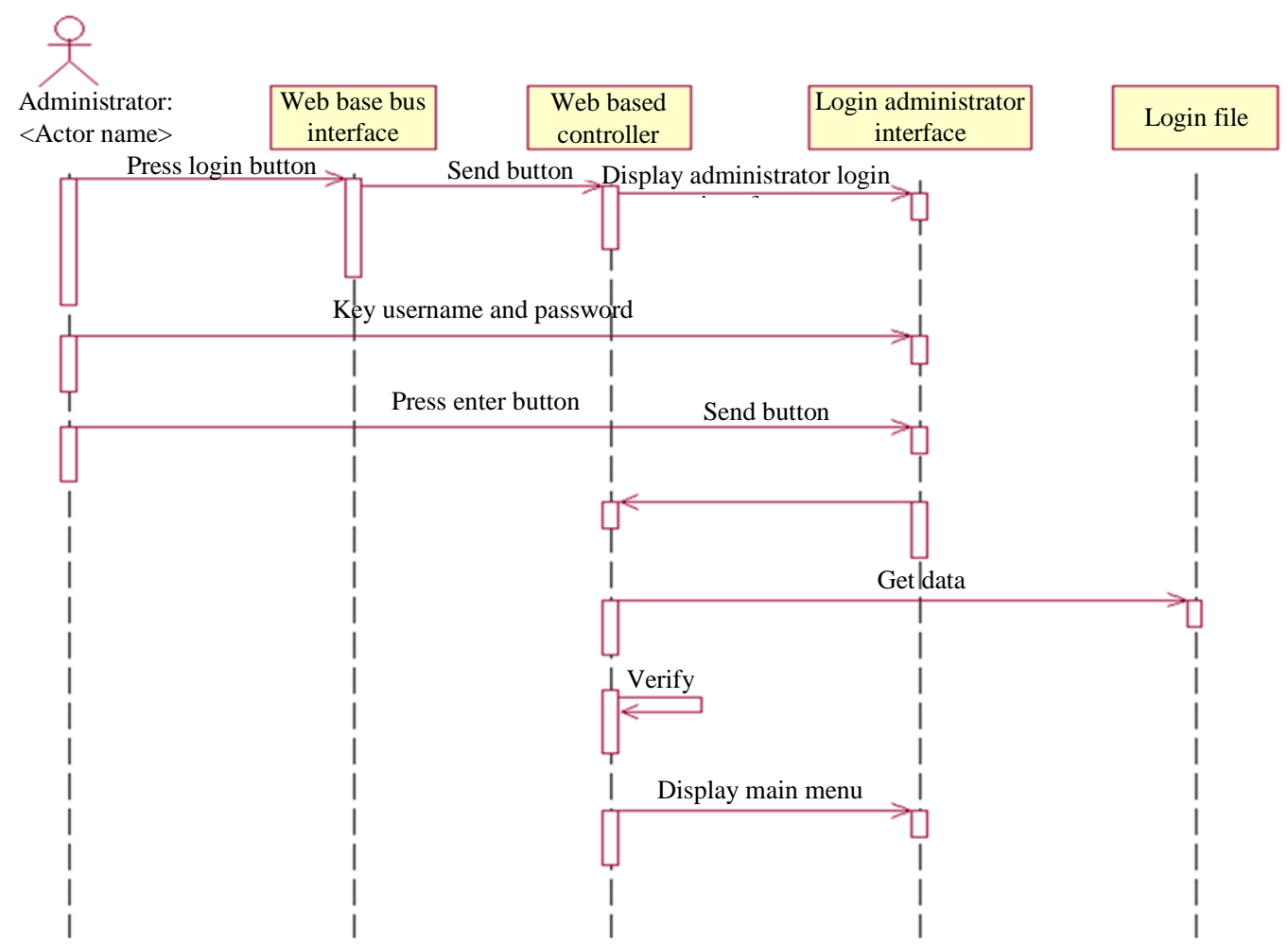

Fig. 2: Login as administrator (It shows the first step where the administrator must enter her/his name and password. After that, the prototype check the data that entered is it true or not)

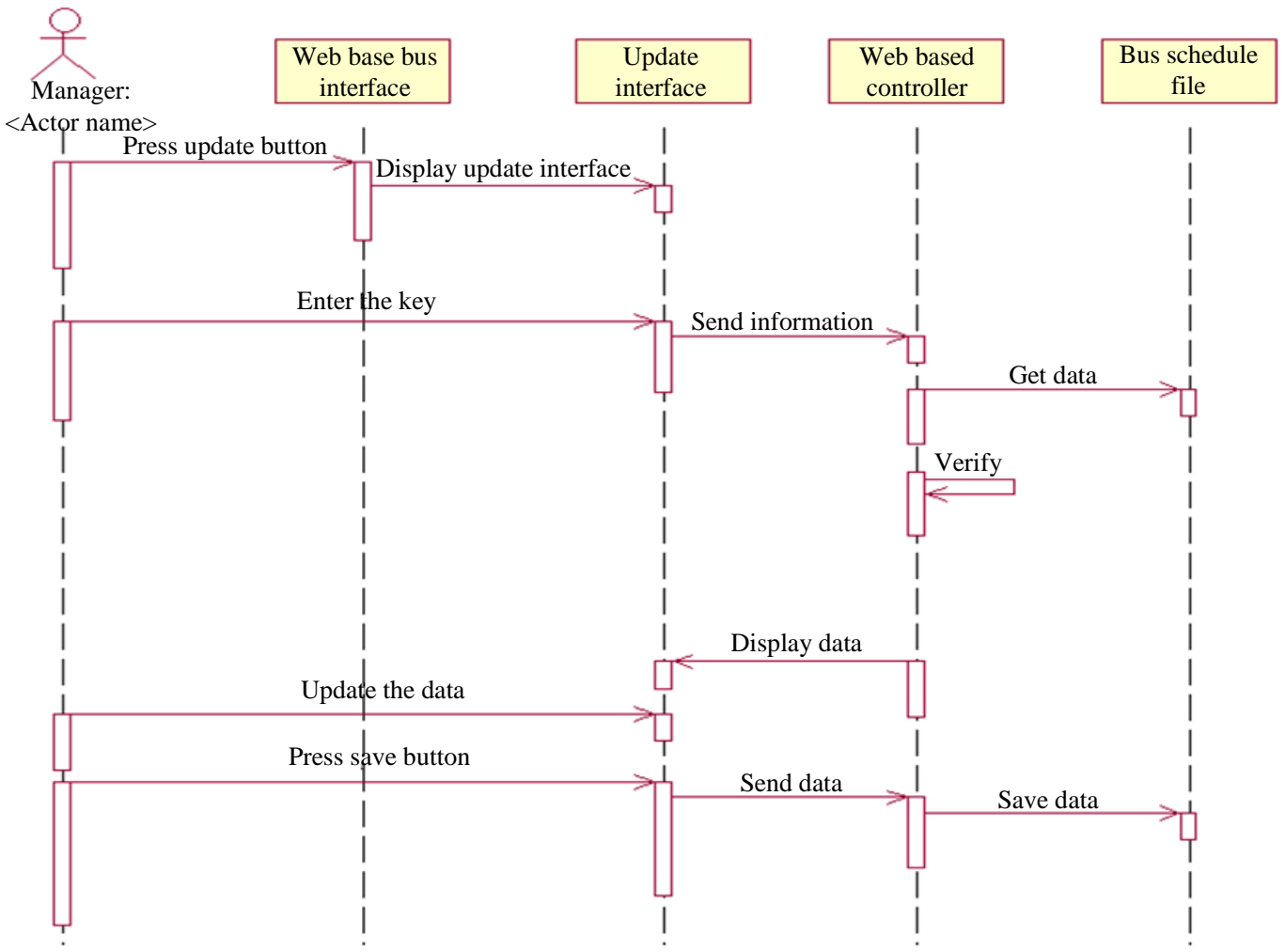

Fig. 3: Update Bus schedule (The steps to update bus schedule through enter the key by manager) 


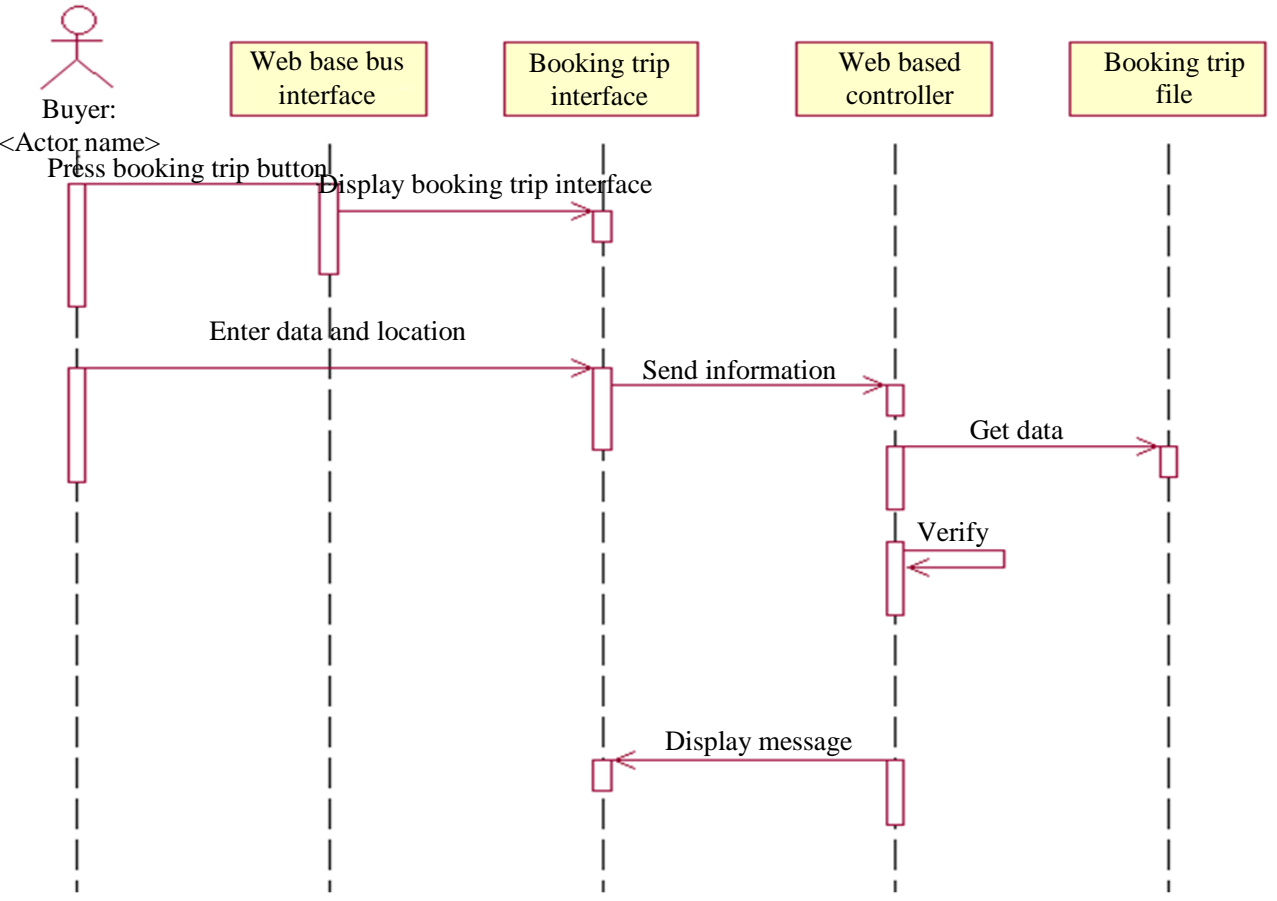

Fig. 4: Booking trip (The steps to make reservation from the system, start when the buyer press booking Trip button. Then the Buyer enter data and location)

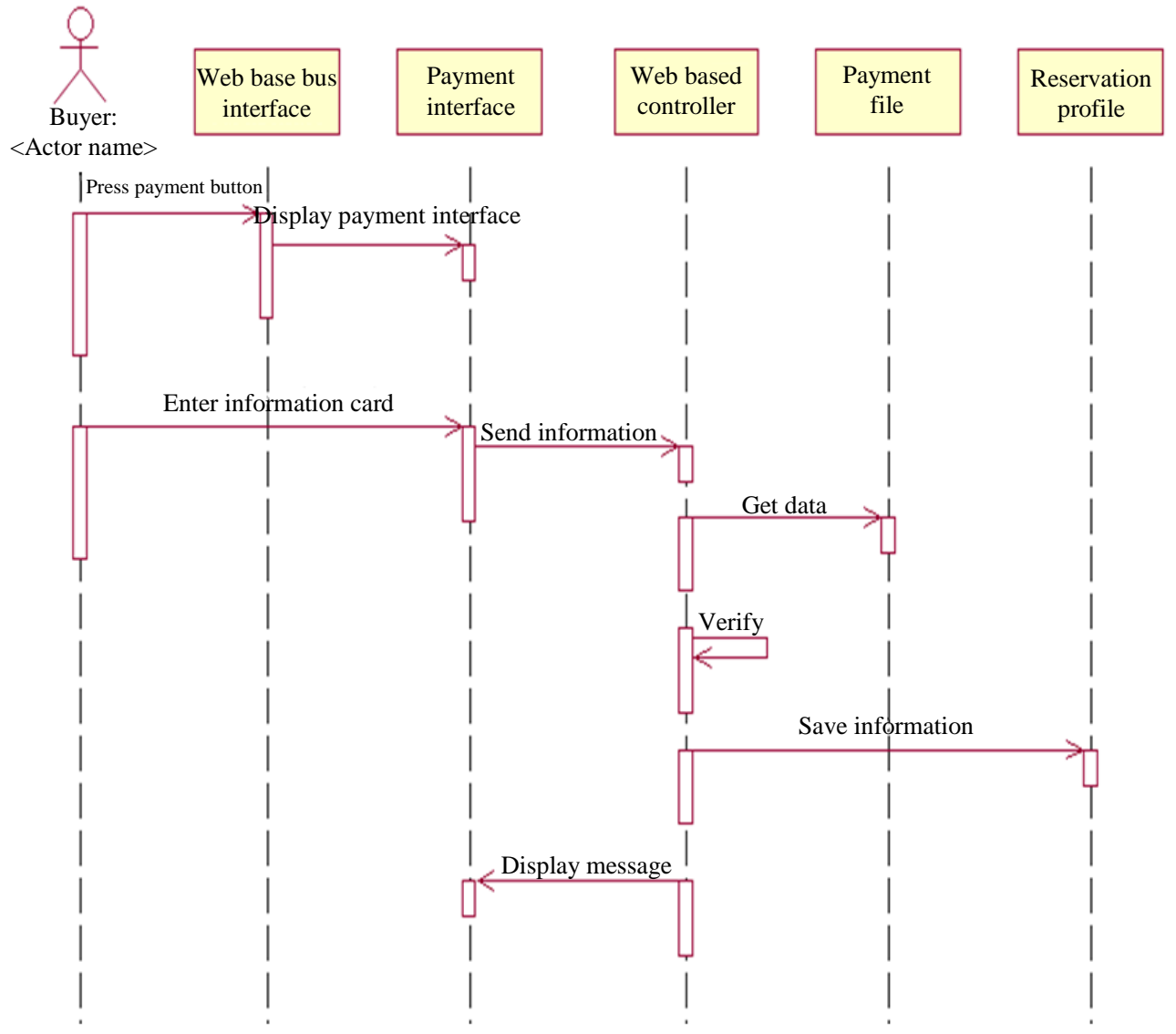

Fig. 5: Payment (The steps to make payment from the system, start when the buyer payment button) 


\section{Activity Diagram}

Describes the activity diagram for the Buyer actor login with web based bus reservation system as shown in Fig. 6. The buyer makes reservation as shown in Fig. 7. The administrator interaction system and the manager interaction system activity diagram is shown in Fig. 8 and Fig. 9 respectively.

\section{Class Diagram}

It explains the static structure of the system's product classes and portrays all connections among those classes, including the association, aggregation and generalization relationships. The following is an elevated level class diagram for the web based bus reservation system. This diagram portrays the connection between various classes inside the framework, as well as the connection between the Administrator, Buyers and Manager with the patient and the web based bus reservation system controller and interface. One can see the usefulness each class has by taking at the associated functions. The variety is additionally appeared to help comprehend the framework better. It is clear that the web based bus reservation system itself assumes a focal job in the general diagram. The vast majority of the usefulness goes through it. UML Class diagram for web based bus reservation system is demonstrated as follows. The different Classes associated with the system are: WB-BRS controller, Administrator, Buyers, Manager, Main page, Bus schedule, Reservation and Payment. The class diagram for web based bus reservation system is shown Fig. 10.

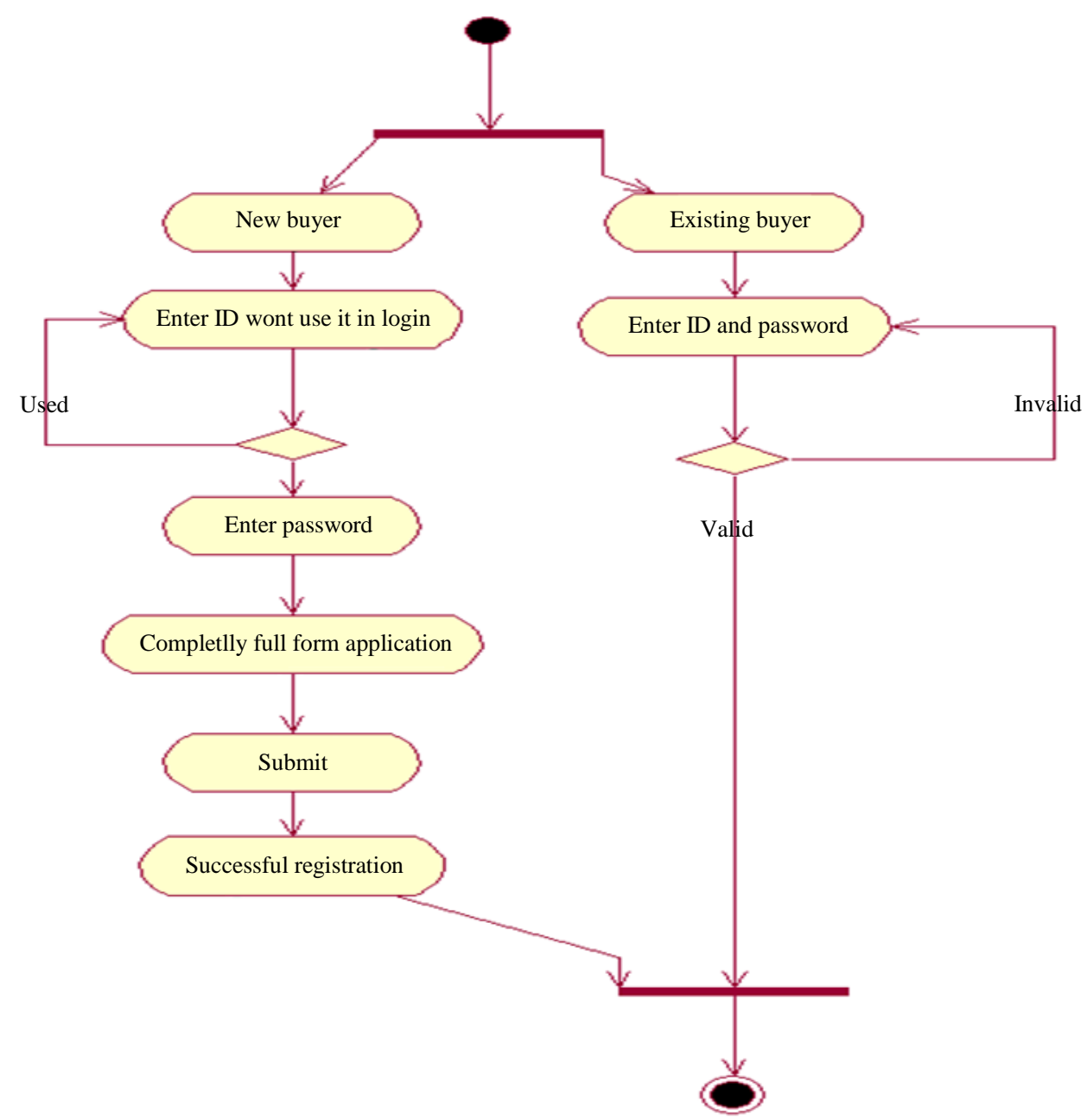

Fig. 6: Buyer Actor login (Figure 6, describes how the buyer login. Two types of login for a new buyer and existing buyers to access privileges to functions in the web based bus reservation system. For the existing buyer should enter the user name and password to access the system while the new buyer should register by entering username and password and fill the Registration form) 


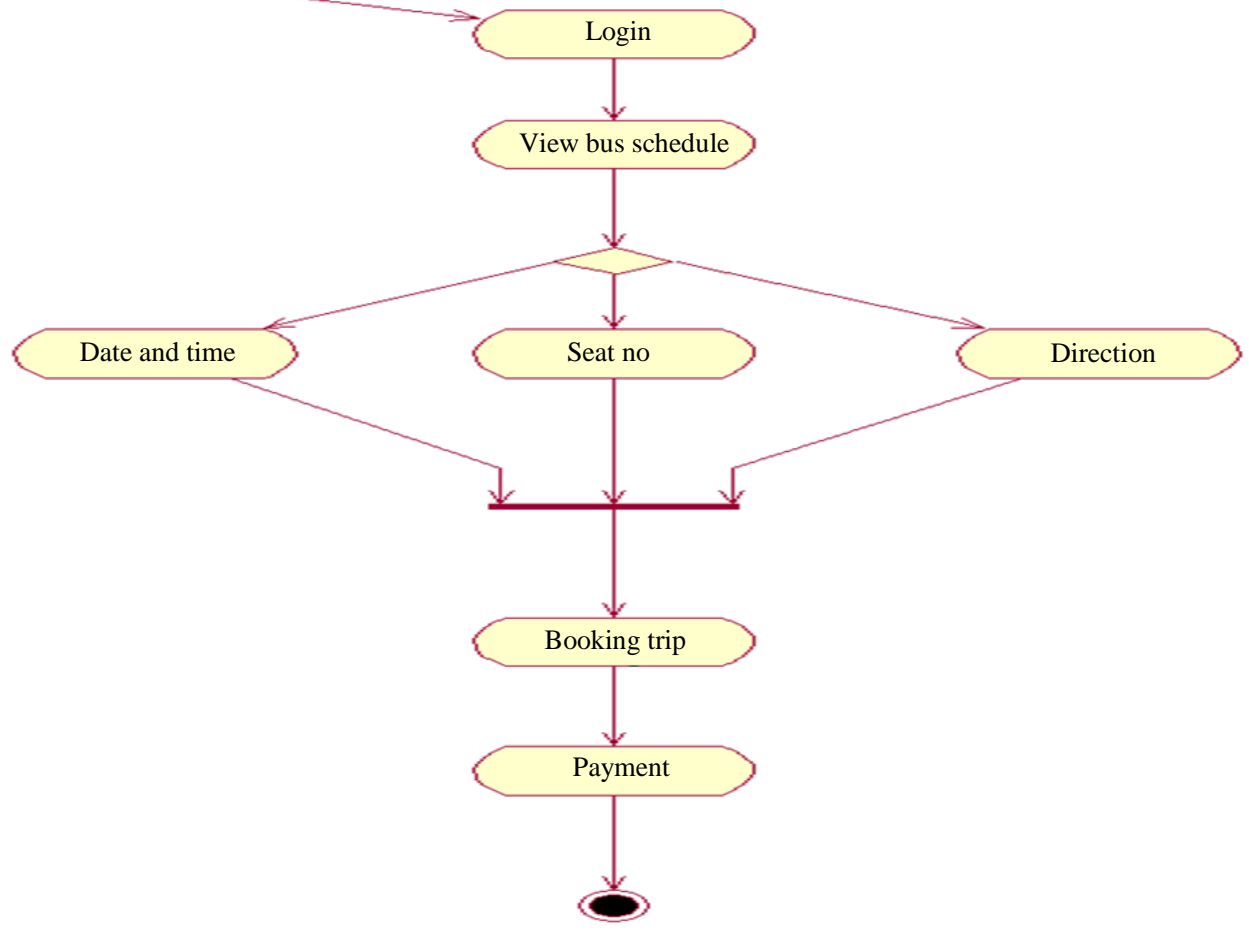

Fig. 7: Buyer makes reservation (In the above Buyer makes reservation activity diagram, seven activities are specified. When the Buyer view bus schedule checking process begins buyer select the date and time, seat No and direction for the trip for booking trip then the buyer should pay. After performing the activity, finally, the process is terminated at termination node)

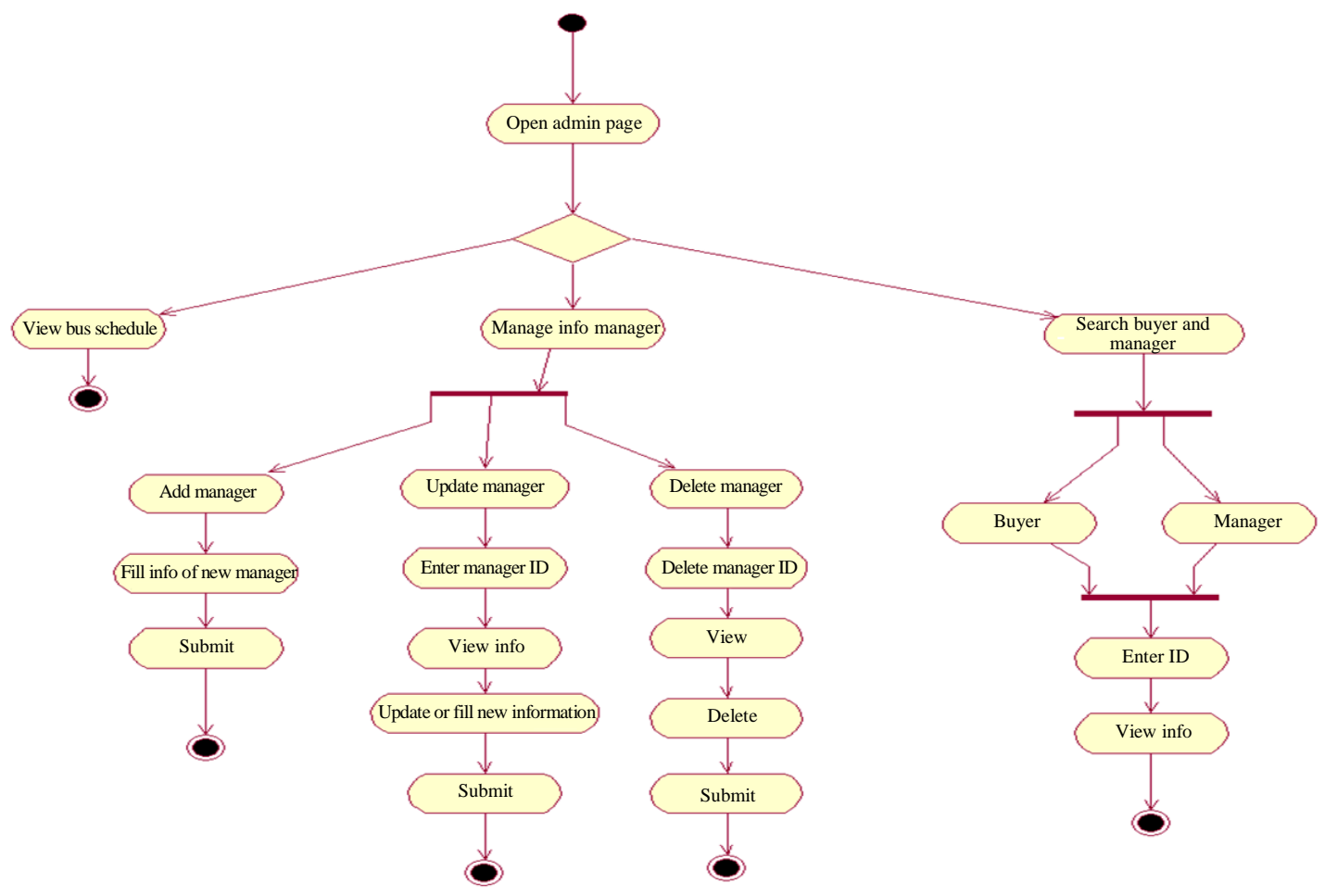

Fig. 8: Administrator interaction system 


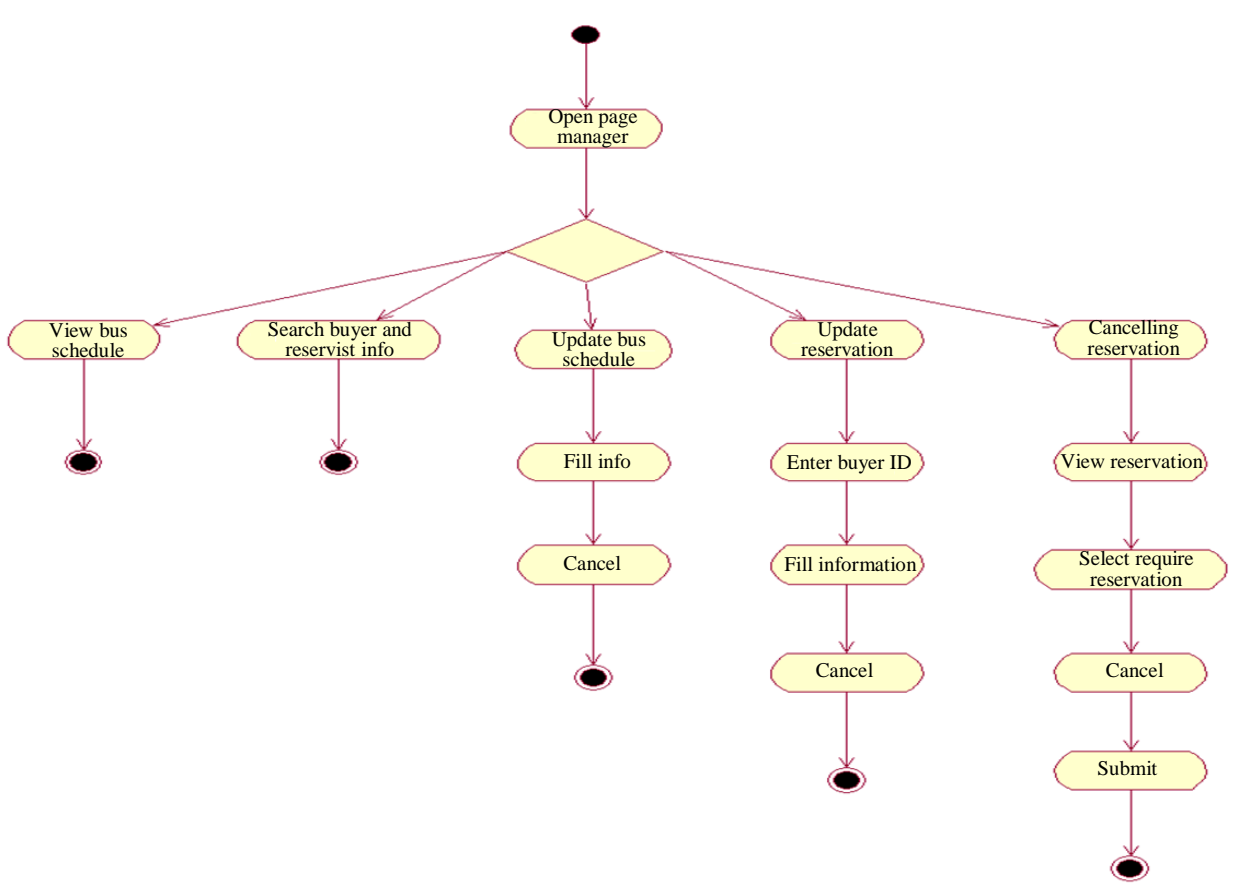

Fig. 9: Manager Interaction system

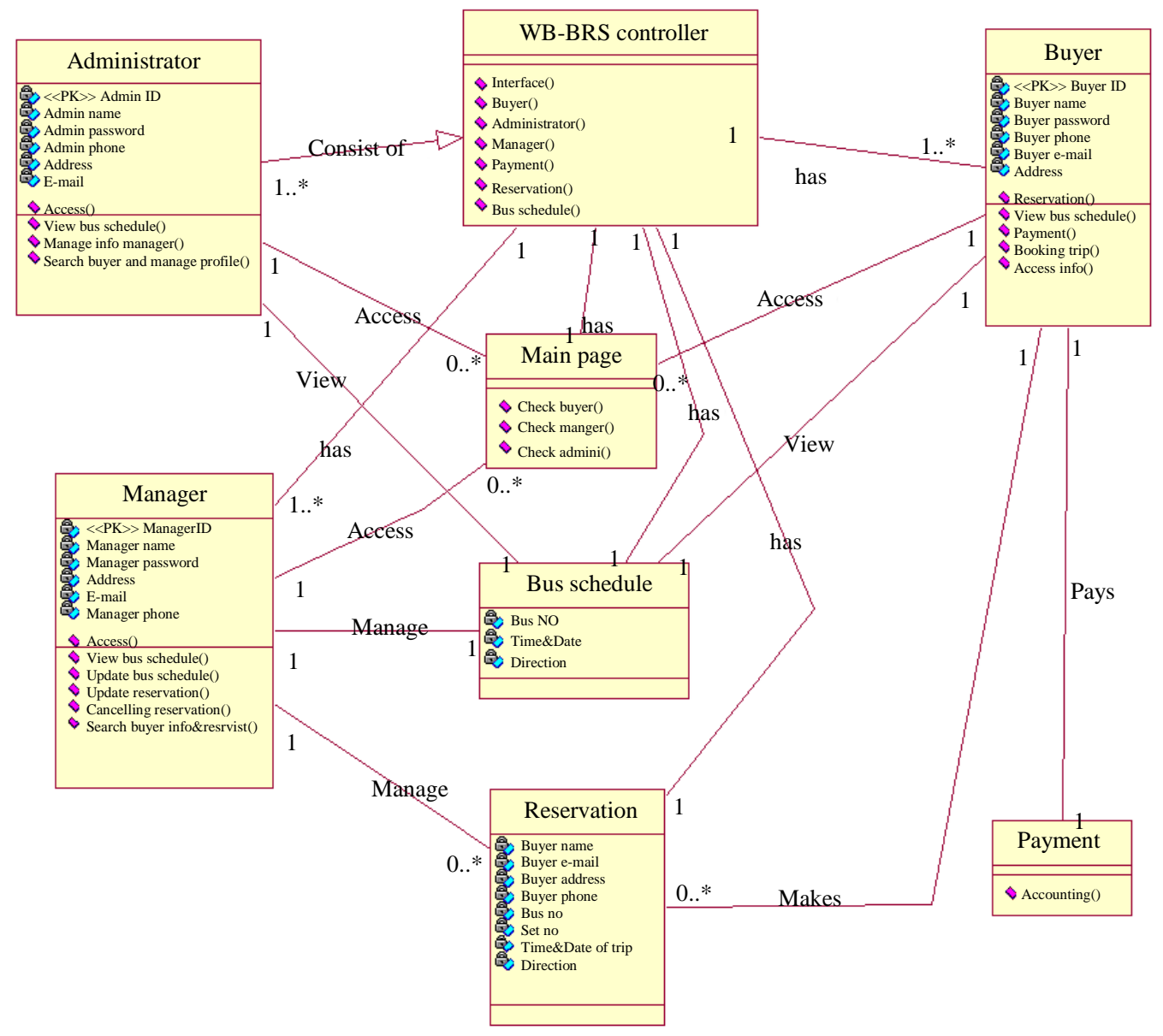

Fig. 10: Class diagram 


\section{Conclusion}

Bus reservation systems are becoming increasingly important; nevertheless, the means for their requirements are still underdeveloped. Hence, having clear and standardized behavioral requirements of bus reservation system would make it possible to determine the properties and make them more comprehensive and less expensive. The unified modeling language is a powerful demonstrating language. It utilizes many modern displaying strategies and is generally applied to various areas. Nowadays in industry reasonably, of what might be approximately delegated framework particular is performed with UML traces. The UML recommends a standard arrangement of graphs and a documentation for demonstrating object-situated frameworks and portrays the principal semantics of what these diagrams and symbols mean. It is increasing wide acknowledgment for the portrayal of building antiques in OOP. Therefore, this study is presented web based bus reservation system with UML, an extension to UML covering the principle parts of reservation system at the different perspectives and diagrams of UML. The use of web based bus reservation system with UML was illustrated using a web based bus reservation system example to have meaningful and standardized behavioral specifications of web based bus reservation system would make it practical to decide the properties and empower progressively exhaustive and less exorbitant. Web based bus reservation system-UML help to make sense of what truly requirement for dissecting, structuring and displaying Web based bus reservation system.

In this study illustrated Web based bus reservation system-UML using to have meaningful and standardized behavioral specifications of resevation system would make it feasible to determine the properties and enable more thorough and less costly. Web based bus reservation system-UML help to figure out what really need for analyzing, designing, modeling and figure out how to take something that is complicated, even messy and turn it into something precise enough that can do.

\section{Acknowledgement}

We would like to thank College of Sciences and Arts at Unaizah, Qassim University, Kingdom of Saudi Arabia.

\section{Author's Contributions}

Hussain Mohammad Abu-Dalbouh: The author contributed to the review the various published articles in the field. Designed the study, Contributed to the search and analysis system by used UML method and writing of the manuscript and final approval.

Sulaiman Abdullah Alateyah: Designed the research plan and organized the study, helped shape the research and comments on writing and provided critical feedback and writing of the manuscript and final approval.

\section{Ethics}

This article is original and contains unpublished material. The corresponding author confirms that all of the other authors have read and approved the manuscript and no ethical issues involved.

\section{References}

Abu-Dalbouh, H. and M. Almueit, 2013. Designing mobile tracking solution in monitoring patients. Proceedings of the 6th International Conference on Information Technology, (CIT' 13), Jordan.

Abu-Dalbouh, H., 2014a. M-TOPP-UML: An extension to UML for the modeling of mobile tracking on patient progress system. Res. J. Applied Sci. Eng. Technol., 7: 1388-1394. DOI: 10.19026/rjaset.7.406

Abu-Dalbouh, H., 2014b. A proposed mhealth model for improving the quality care in hospitals. Res. J. Applied Sci. Eng. Technol., 7: 1401-1405.

DOI: $10.19026 /$ rjaset.7.408

Abu-Dalbouh, H.M. and G.A. Nehal Aldowighri, 2018. Generic modelling using UML extensions for queens challenge puzzle game from 1 to 25 levels system. Int. J. Software Eng. Applic., 9: 31-39. DOI: $10.5121 /$ ijsea.2018.9603

Abu-Dalbouh, H.M., 2013. A questionnaire approach based on the technology acceptance model for mobile tracking on patient progress applications. J. Conput. Sci., 9: 763-770.

DOI: 10.3844 jessp.2013.763.770

Abu-Dalbouh, H.M., 2019. Developing mobile tracking applications for patient treatment. Comput. Inform. Sci., 12: 12-22. DOI: 10.5539/cis.v12n1p12

Abu-Dalbouh, H.M., M. Al-Matrouk, N. Al-Zwaid and A. Al-Handi, 2019. Proposal of a standardized electronic health record for kingdom of saudi arabia. J. Comput. Sci. J. Comput. Sci., 15: 566-581. DOI: $10.3844 /$ jcssp.2019.566.581

Abu-Dalbouh, H.M., S.M. Alsulaim, S.A. Aldera, S.E. Alqaan and L.M. Alharbi et al., 2020. An application of physics experiments of high school by using augmented reality. Int. J. Software Eng. Applic., 11: 37-49. DOI: 10.5121/ijsea.2020.11103

Booch, G., J.E. Rumbaugh and I. Jacobson, 2005. The Unified Modeling Language User Guide. 2nd Edn., Addison Wesley Professional,

ISBN-10: 8131715825, pp: 496.

Colomb, R., K. Raymond, L. Hart, P. Emery and C. Welty et al., 2006. The object management group ontology definition metamodel. Ontol. Software Eng. Software Technol. 
Fuentes-Fernández, L. and A. Vallecillo-Moreno, 2004. An introduction to UML profiles. UML Model Eng., 2: 6-13.

Lucas, F.J., F. Molina and A. Toval, 2009. A systematic review of UML model consistency management. Inform. Software Technol., 51: 1631-1645.

DOI: 10.1016/j.infsof.2009.04.009

Mohagheghi, P., V. Dehlen and T. Neple, 2009. Definitions and approaches to model quality in model-based software development-a review of literature. Inform. Software Technol., 51: 1646-1669. DOI: 10.1016/j.infsof.2009.04.004

Mubin, S.A., A.H. Jantan, R. Abdullah and A. Kamaruddin, 2015. UML-based navigational design approach for modeling complex interactions in web applications. Proceedings of the Malaysian Software Engineering Conference, Dec. 16-17, IEEE Xplore Press, Kuala Lumpur, Malaysia, pp: 60-63. DOI: 10.1109/MySEC.2015.7475196

Oestereich, B., 2002. Developing Software with UML: Object-Oriented Analysis and Design in Practice. 1st Edn., Addison-Wesley Longman Publishing Co., Inc. 020175603X, pp: 320.
OMG, 2000. Omg unified modeling language specification. Reported on.

Pathak, N., B. Singh and G. Sharma, 2017. UML 2.0 based framework for the development of secure web application. Int. J. Inform. Technol., 9: 101-109. DOI: $10.1007 / \mathrm{s} 41870-017-0001-3$

Pretorius, R. and D. Budgen, 2008. A mapping study on empirical evidence related to the models and forms used in the UML. Proceedings of the 2nd ACMIEEE International Symposium on Empirical Software Engineering and Measurement, (SEM' 08), ACM, pp: 342-344.

DOI: $10.1145 / 1414004.1414076$

Rumbaugh, J., I. Jacobson and G. Booch, 1999. The Unified Modeling Language (UML) reference manual. Addison Wesley Longman Inc, USA, Massachusetts.

Scott, K., 2001. UML Explained. Addison Wesley. 